\title{
Improving Industrial Policy Intervention: The Case of Steel in South Africa
}

\section{Wouter Bam \& Karolien De Bruyne}

To cite this article: Wouter Bam \& Karolien De Bruyne (2019) Improving Industrial Policy Intervention: The Case of Steel in South Africa, The Journal of Development Studies, 55:11, 2460-2475, DOI: $10.1080 / 00220388.2018 .1528354$

To link to this article: https://doi.org/10.1080/00220388.2018.1528354

\section{+ View supplementary material}

曲 Published online: 17 Oct 2018.

Submit your article to this journal $\square$

Џlll Article views: 297

Q View related articles ๘

View Crossmark data \lceil 


\title{
Improving Industrial Policy Intervention: The Case of Steel in South Africa
}

\author{
WOUTER BAM @* \& KAROLIEN DE BRUYNE** \\ *Department of Industrial Engineering, Stellenbosch University, Stellenbosch, South Africa, ${ }^{* *}$ KU Leuven, Faculty of \\ Economics and Business, Brussels, Belgium
}

(Original version submitted March 2018; final version accepted August 2018)

\begin{abstract}
We contribute to the lack of tools to support efficient industrial policy-making, especially in the mineral beneficiation policy literature. To address this vacuum, we adapt the product space analysis approach to incorporate an input-output value chain lens. This framework is applied to the case of steel in South Africa to derive novel insights regarding the (in)efficiency of implementing a downstream linkage-based beneficiation policy. Our dynamic analysis approach allows for interactions with the rest of the product space. We find that a 'leap-frogging' approach to development within the value chain may be more optimal than a strict beneficiation based industrial policy.
\end{abstract}

\section{Introduction}

For decades, globalisation was considered necessary and sufficient to drive development. Recently, an increasing trend towards re-acknowledging the role that government intervention, and industrial policy in particular, can and should play in supporting the development of countries has emerged (Chang, 2003; Cimoli, Dosi, \& Stiglitz, 2009; Horner, 2017). This narrative suggests that policies should target the market failures that restrict growth, ${ }^{1}$ which developing countries in particular are faced with (Hausmann \& Rodrik, 2006). These policies might be horizontally (economy wide) or vertically (sectorally) targeted (Spring, Hughes, Mason, \& McCaffrey, 2017). Without neglecting the importance and complementarity of both policy types, the focus here is on vertical industrial policy decisionmaking.

Government intervention in the development of countries has been emphasised by a diversity of works. These range in terms of level of analysis from global (Barrientos \& Smith, 2007) to regional (Peck, Connolly, Durnin, \& Jackson, 2013) and community level (Rolfe, 2013). Secondly, their foci vary from economic considerations (including economic growth (Chang, 1993), inequality (Piketty \& Saez, 2006) and job creation (Hilson \& McQuilken, 2014)), social considerations (including labour conditions (Barrientos \& Smith, 2007), skills development (Ramirez \& Rainbird, 2010), and health (Calderon, Harris, \& Kirsch, 2016)), environmental considerations (including addressing the loss of fauna and pollution (Anejionu, Ahiarammunnah, \& Nri-Ezedi, 2015)) and the integration of these concerns (through concepts such as the triple bottom line of sustainability (Allwood, Laursen, Russell, de Rodríguez, \& Bocken, 2008; Du Plessis \& Bam, 2018)).

Correspondence Address: Wouter Bam, Department of Industrial Engineering, Stellenbosch University, 4th Floor Mechanical and Industrial Building, Joubert Street, Stellenbosch, 7600, South Africa. Email: wouterb@sun.ac.za

Supplementary Materials are available for this article which can be accessed via the online version of this journal available at https://doi.org/10.1080/00220388.2018.1528354 
This diversity underlines the multitude of factors relevant to the industrial policy-making process. Tackling all these objectives concurrently is beyond the scope of this paper. Instead, we focus on one of these - national economic growth.

One challenge to policy-making is the lack of efficient tools to support improved decision-making. This is especially relevant with regards to identifying industries that a country can and should support, as countries are indeed 'doomed to choose' certain sectors over others (Hausmann \& Rodrik, 2006). Given the vacuum of appropriate tools, policy-makers are forced to revert to intuitive approaches that potentially lead to sub-optimal results. A key example of such an approach that has delivered mixed results is the policy of beneficiation (Morris, Kaplinsky, \& Kaplan, 2012). This refers to mineral producing countries aiming to 'capture more value' from their mineral resources by encouraging (or even forcing) the downstream value added to minerals before export (Bam \& De Bruyne, 2017).

We aim to contribute to the growing literature that seeks to provide better tools for guiding industrial policy-making along various dimensions to address this vacuum. Specifically, our study is positioned within the capability theory literature. This implies that we focus our analysis on the contribution that the development of particular export industries can make to the development of a country's economic capabilities to support future economic growth at a national level. This is particularly relevant, as developing countries can become caught in a quiescence trap if they do not continually develop capabilities that support the production and export of more complex products (Hausmann \& Hidalgo, 2011).

In this paper, we extend the existing product space approach to the analysis of input-output defined value chains. Our input-output product space (IO-PS) framework has the potential to better support countries (developing countries in particular) to develop more nuanced industrial policy. The framework seeks to support the targeting of industries that complement countries' existing production structures in order to improve developmental pathways. We highlight the utility of the framework by applying it to a mineral value chain in a developing country. As such, we are able to contrast our results with those that would be obtained if a downstream linkage-based beneficiation-type industrial policy had been followed. We thus specifically contribute not only to the industrial policy literature related to the product space approach, but to the literature concerned with the debate regarding the merits of following a beneficiation approach to industrial policy as well. The remainder of the paper is arranged as follows: the next section links our paper to the existing literature; Section 3 describes the data and methodology, while Section 4 discusses the results. Section 5 concludes the paper.

\section{Theoretical background}

As background to the paper, we consider three strands of literature: the product space literature; the literature on mapping industry input-output relations; and the literature regarding the (in)effectiveness of beneficiation. In the product space section, we provide a brief description of the metrics relevant to this study. Details on how the product space metrics are calculated, and additional background information are provided in the Supplementary Materials.

\subsection{Product space}

The product space concept introduced by Hidalgo, Klinger, Barabasi, and Hausmann (2007), is underpinned by the concepts of proximity and revealed comparative advantage (RCA). Most work on the product space, including the seminal work by Hidalgo et al. (2007), employ the Balassa (1965) definition of RCA. In this definition, the $R C A_{c, i}$ is the ratio of the export of a given product $i$ from a country $c$ as a portion of the total exports of that country, to the global value of export of that product as a portion of total world exports.

Hidalgo et al. (2007) define $R C A_{x_{i}}$ for a country $c$, as equal to 1 when $R C A_{c, i}>1$ and $R C A_{x_{i}}$ for a country $c$, as equal to 0 when $R C A_{c, i} \leq 1$. The value of 1 is thus assigned when a country can be 
considered to have a revealed comparative advantage in product $i$ and 0 if it cannot. Using this restated definition, they define the concept of proximity, where proximity between two products ( $i$ and $j$ ) is a measure of the probability that a country will have an RCA in a product $i$ if it also has an RCA in a product $j$ or vice versa, whichever is the minimum. If all countries that produce the product $i$ also produce the product $j$, their proximity will be equal to 1 . If no country produces both products, the proximity of the products will be 0 .

Using these proximity values, Hidalgo et al. (2007) visualise what they call the product space by calculating and plotting the maximum spanning tree of the product proximities and superposing the links between products where the proximity between these products is above a certain threshold. From the resulting network, it is clear that certain products can be considered to be in the periphery and others in the core of the product space. Referring to capability theory, products in the periphery can be considered to require capabilities that do not enable the countries that produce them to produce many other products (Hidalgo \& Hausmann, 2009). For example, producing cork (located in the periphery of the product space) does not require capabilities that support the production of many other products. In contrast, competitively exporting vehicles (located in the core of the product space) is likely to lead to capabilities that could support the production of a variety of other products such as piston engines and automotive related parts; laboratory related equipment or even boilers and related products - all products that have a relatively high proximity to vehicles. In general, the core is formed by metal products, machinery, and chemicals, while the periphery is formed by agricultural, fishing, mining, and extractive activities (Felipe, Kumar, Abdon, \& Bacate, 2012; Hidalgo \& Hausmann, 2009).

Distance is a metric that describes the position of a country in the product space relative to some product $j$ for which it does not yet have an RCA. In particular, it is the ratio of the sum of proximities between product $j$ and all the products for which a country has an RCA to the sum of proximities between product $j$ and all the products in the product space. Thus, if a country has a large distance to some product $j$, this implies that it does not have an RCA in many of the proximate products to product $\mathrm{j}$ and it could be expected that it would be more difficult to acquire an RCA for it than for some product with a smaller distance value (Hausmann et al., 2011).

Two further central metrics in the product space literature are the product complexity index (PCI) and country economic complexity index (ECI). Hidalgo and Hausmann (2009) showed that such complexities can be calculated iteratively through the method of reflections. In this method, product complexity is a function of the complexity of the countries that produce it and the country complexity is a function of the complexity of the products that it produces. These metrics are endogenous, correct for population size, and are able to predict economic growth. This makes it useful for identifying products that can support development (Felipe et al., 2012; Hausmann \& Klinger, 2009; Hidalgo \& Hausmann, 2009).

Despite the availability of competing metrics (as described in the Supplementary Materials), we use the original economic complexity index developed by Hidalgo and Hausmann (2009) as it is the most established metric and has been shown to be robust and near optimal (Albeaik, Kaltenberg, Alsaleh, \& Hidalgo, 2017; Mariani, Vidmer, Medo, \& Zhang, 2015; Pugliese, Zaccaria, \& Pietronero, 2016).

Two other metrics for evaluating the strategic importance of development opportunities are the opportunity value and opportunity gain, described in Hausmann et al. (2011). The opportunity value of a country is a function of the product of the complement of distance to all products for which it does not have an RCA and the complexity of these products. Thus, a high opportunity value of a country implies that the products with low distances for that country generally have high complexity values. Opportunity gain, then, provides an indication of how much the attainment of an RCA in a specific product for which a country does not yet have an RCA, will contribute towards increasing that country's opportunity value.

\subsection{Input-output relations}

Various fields of literature resort to conceptualisations of supply chains. These include development studies, management, economics, and supply chain management. Supply chains, in this 
context, can be viewed as sequential activities by distinct firms that transform inputs to outputs that again act as input to downstream activities, which eventually satisfy some final demand (Henderson, Dicken, Hess, Coe, \& Yeung, 2002). Much cross pollination between these fields has taken place (and has even been advocated for (Holweg \& Helo, 2014)). Regardless, such studies can be classified into various schools of thought, each with their own collection of tools and terminology. In the development literature, much attention has recently been focused on the 'global value chain' analysis (Gereffi, Humphrey, \& Sturgeon, 2005) and 'global production network' (Henderson et al., 2002) frameworks. In the management literature, the value chain definition of Porter (1985) has been of great importance in establishing the term. In different fields of economics, the work of Hirschman (1981) and Leontief (1936) both established different conceptual approaches to supply chain analysis. Even within supply chain management, various conceptualisations of the supply chain exist depending on the application. These include the closed-loop supply chain (Seuring, 2013) and the international manufacturing network (Rudberg \& Olhager, 2003). We draw upon the simple structure that underpins most of this research, namely, the conceptualisation of different nodes that are connected through input-output relationships. We employ this structure as it allows us to understand how economies transform various inputs and raw materials into final goods. In our terminology, we use the term value to highlight the focus of identifying the value capture that activities imply (similar to Bam, 2016; Bam \& Schutte, 2017; Henderson et al., 2002). We use the term chain to highlight the input-output relations between products when considered from a beneficiation perspective.

\subsection{Beneficiation}

Beneficiation can be broadly defined as the local value add to mineral-based products within a country before export (Department: Mineral Resources, 2011). The term is often employed in discussions regarding the merits of developing mineral producing countries further processing their extracted resources before export. In academia, this is often framed in the context of the 'downstream linkages' that can be attained from mining activities as defined by Hirschman (1981) (Morris et al., 2012).

The debate regarding the merits of the policy of seeking to further process minerals in the extracting country for socio-political reasons is not new (Radetzki, 1977). A 1984 United Nations (UN) study on 'Mineral Processing in Developing Countries' (United Nations, 1984) examined 'the factors which affect the location of mineral processing in developing countries' (p. 1). The argument for this was that developing countries produce a large percentage of minerals but are not largely involved in the processing thereof to final products. Therefore, they could better diversify their economies, industrialise, reduce their dependence on industrial countries, develop transferable skills, and increase economic rents by processing their minerals themselves. The same study (and authors such as Crowson, 2008) explore some of the many reasons why such beneficiation might be difficult (and very costly) to achieve. Regardless, in the 2000's, the resource boom again saw an increase in beneficiation policies being implemented and considered by a variety of countries (Bam \& De Bruyne, 2017). Despite the clear interest of governments in implementing beneficiation policies, some authors have completely rejected beneficiation as a basis for policy-making (Hausmann, Klinger, et al., 2008). Despite these diverging views, the emerging consensus appears to be that there is a place for beneficiation-based policy, but that it is not advisable across the board. Rather, opportunities should be very carefully evaluated. Consequently, there is a sustained call in the literature for a more nuanced approach in dealing with opportunities for beneficiation (BocoumKaberuka, 1999; Ivanova, 2014; Morris \& Fessehaie, 2014; Morris et al., 2012; Reinhardt, 2000). Overall, the analytical tools available for guiding such policy are still lacking. We thus aim to specifically address this gap in the beneficiation literature by proposing a novel analysis approach to answering this question from a product space perspective. In particular, we aim to provide a 
complementary perspective to the existing global value chain and linkage-based approaches most commonly applied in the debate (Bam \& De Bruyne, 2017).

\section{Data and methodology}

The data used for this study was downloaded from the MIT Observatory for Economic Complexity (OEC) website (https://atlas.media.mit.edu/en/resources/data/). In particular, the HS6 1992 Revision data at four-digit depth was used, which the OEC sourced from the BACI International Trade Database. The MATLAB code used for the analysis of the data is available in the Supplementary Materials of this article.

Our methodology consists of three phases. First, a suitable case was selected (discussed in Section 3.1). Second, we constructed a novel, granular input-output map of the industry (discussed in Section 3.2). This not only enabled the evaluation of the industry from an input-output value chain perspective, but also required the definition of product categories that consist of products directly linked to international trade codes. This was necessary to enable the application of a product space perspective. The final phase of the methodology entailed a detailed product space driven analysis of the focal country and value chain (discussed in Section 3.3). The application of this input-output product space (IO-PS) framework to a representative mineral value chain case study provides a new perspective on the beneficiation debate.

\subsection{Case selection}

Four aspects were considered in the selection of a case study country. Subsequently, South Africa was chosen as the ideal candidate. Firstly, due to the focus of the study, the country was required to be a developing country - a country with a relatively low complexity value (South Africa has a negative economic complexity, -0.3 (OEC, 2017)). This ensured that the country could be expected to have a relatively small footprint ${ }^{2}$ of complex products in the product space - enabling simulations of the attainment of new, more complex products. Secondly, given the focus on beneficiation, mineral resources had to constitute an important part of the country's exports (mineral and precious metals exports accounted for 33\% of South African exports in 2016 (OEC, 2017)). Thirdly, the country needed to have sufficient data quality and availability for analysis (South Africa is included in UN COMTRADE, The Center for International Data, and the BACI International Trade Databases). Finally, the country must have considered beneficiation policy in the past, making the case study results directly applicable to the beneficiation debate (South Africa's Department of Mineral Resources [DMR] has published a 'Beneficiation Strategy' aiming to provide a blueprint toward increasing beneficiation in the country (Department: Mineral Resources, 2011))

Four further aspects were considered to select a suitable mineral value chain for analysis, resulting in the selection of the steel value chain. Firstly, South Africa would need to have an RCA in the production of the mineral (South Africa's RCA for iron ore is 7.58). Secondly, South Africa must not yet have an RCA for the entire value chain (South Africa has an RCA $>1$ in only 39 of 272 products that can be considered part of the steel value chain). Third, the value chain should on average have a relatively high complexity in order to ensure that it is worth pursuing from a development perspective (average complexity of products in the steel value chain is $0.61-$ substantially above the complexity of South Africa). Fourth, the industry should have a relatively large international trade value to ensure the industry is internationally important and relevant (products considered part of the steel value chain had a global export value of US\$7 118 billion in 2014, accounting for $40 \%$ of global exports). Finally, the industry should ideally have been identified by the South African government as an industry of interest, in order to ensure the maximum relevance of the results (the steel industry is and has in the past number of years been directly and indirectly targeted as part of the South African government's 'Industrial Policy Action Plan' (Department: Trade and Industry, 2017)). 
The case is of further interest as the success of industrial policy at large in South Africa has at best been mixed. The Motor Industry Development Program for instance (deemed by some to be one of the most successful examples) has been assessed both positively (Barnes, Kaplinsky, \& Morris, 2004) and negatively (Barnes et al., 2004) as it has increased productivity and exports but import tariffs on finished vehicles remain high, implying high costs for consumers. Secondly, the Department of Trade and Industry is very much in favour of beneficiation especially in the metals and minerals sector. However, Hausmann, Rodrik, and Sabel (2008) highlight the possible dangers for South Africa of following a classic beneficiation approach. This highlights the need for additional studies to better guide the government's beneficiation strategy and the direct policy relevance of the chosen case.

\subsection{Industry value chain mapping}

In the second phase of the methodology, a novel trade-code based input-output mapping was constructed through a multi-step mapping process. In the first step, the US Bureau of Economic Analysis input-output as well as make and use tables from 2002 were used. These provided a foundation for identifying the industries that are linked through value chain input-output relationships with iron ore, iron, and steel. Using concordance tables, these were then converted to HS trade codes. These mappings were further refined to identify product categories - each representing up to 11 four digit HS trade codes (detailed in Table S1 in the Supplementary Materials) - using detailed industry mappings (Cullen, Allwood, \& Bambach, 2012). The product categories were chosen in order to represent related product groups which could be collectively targeted by sectoral government intervention. Based on the resulting mapping, all excluded two-digit HS trade codes were evaluated to determine whether any had an average proximity to the value chain higher than the average proximity of those already included. Based on these calculations, HS 76 - aluminium and articles thereof - was also included in the mapping. The categories were then divided into tiers based on their input-output relations. Thus, tier $\mathrm{n}$ category products consume products in tier $\mathrm{n}-1$ during production. The resultant industry map was further fine-tuned and validated through discussions with industry experts. The validated mapping provided the foundation for the rest of the analysis.

\subsection{Country specific analysis}

Using the derived input-output mapping, country specific analyses for South Africa could be performed and an IO-PS analysis framework developed. The resulting framework and results are discussed in detail in the following section. The approach focusses on products within each product category for which the country does not yet have an RCA. Three specific metrics were deemed important, namely: i) complexity (due to its importance for understanding the product category's potential contribution to economic growth); ii) distance (as it provides an indication of how difficult it would be to attain the products within a product category from a government perspective); and iii) opportunity gain (as it provides an indication of how much the attainment of products within a specific product category could contribute towards the development of capabilities that could support the attainment of other high complexity products in the future).

\section{Results and discussion}

Combining our granular mapping with metrics from the product space literature, it is possible to indicate the worldwide (i) complexities of each product category; ${ }^{3}$ and (ii) bilateral proximity values larger than or equal to $0.4^{4}$ as shown in Figure 1.

In Figure 1 and throughout the remainder of the text, we use a grey scale to ease the interpretation of results. In each case, the values are shaded on a spectrum ranging from light grey (least desirable from the perspective of a government seeking to intervene in industry), to dark grey (most desirable ${ }^{5}$ ). When the aggregated tier-level metrics in Figure 1 are evaluated, they seem to broadly support the classic 


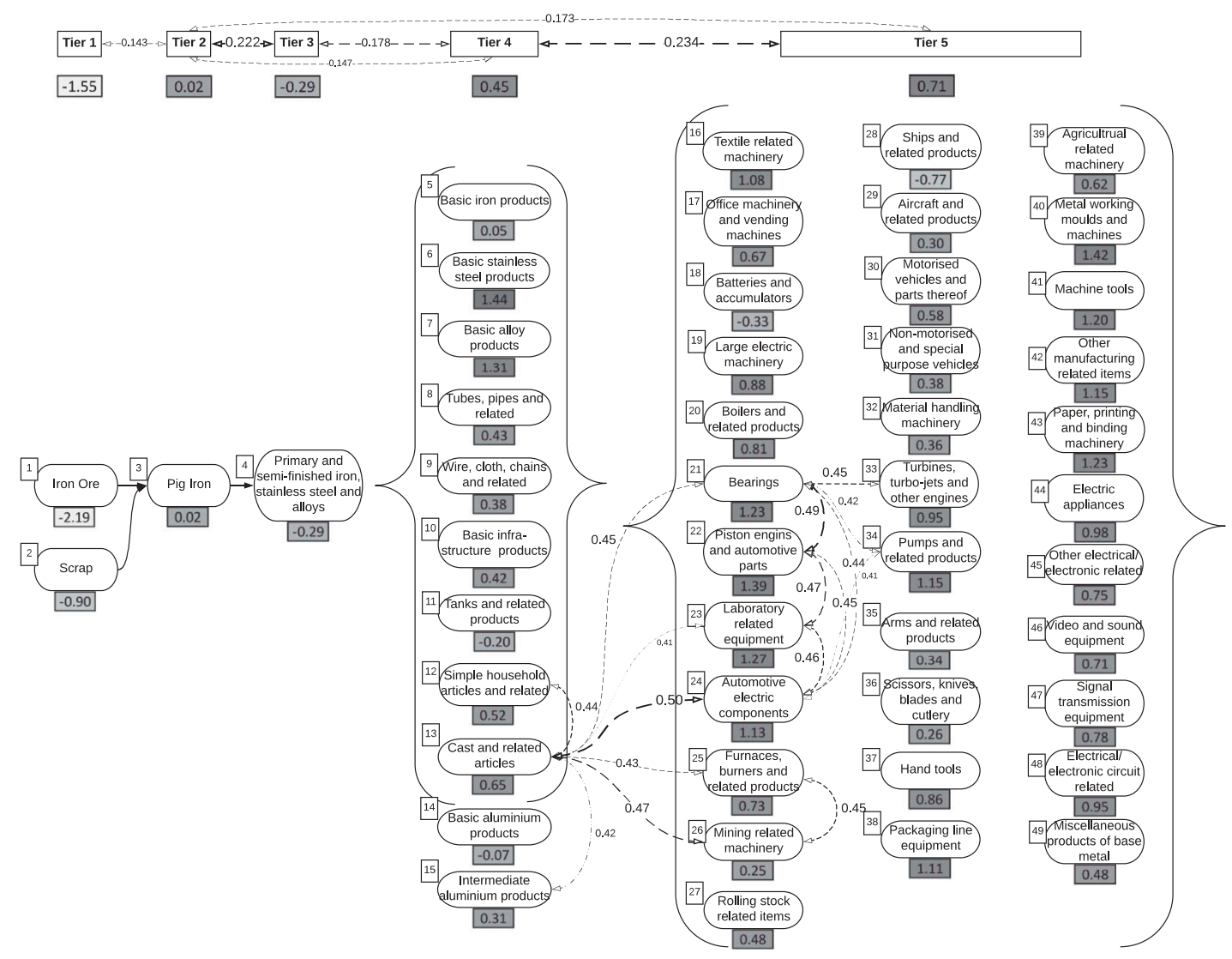

Figure 1. Aggregated (tier-level) and products category level steel value chain with global complexity scores and high proximity values.

beneficiation narrative. The downstream tiers have higher average complexities and the highest proximities between tiers are between those that are adjacent. However, tier 1 - iron ore and scrap is least proximate to the rest of the value chain, again highlighting the difficulty of diversification and beneficiation that many mineral resource countries face. Intuitively, it seems that the logic of targeting input-output linked products in order to move downstream is justified - particularly if the gap from tier 1 to tier 2 can be bridged. However, if the product category level is considered, it is clear that the picture is more complicated. For example, category 28 in tier 5 has a lower complexity than the tier 2 product category. Clearly, selection of which product category/-ies to target at the disaggregated level is significantly more challenging than apparent at the tier level. As a further example, based on Figure 1 (without considering a country's current footprint), one might argue that targeting product categories six and 40 makes most sense from a complexity point of view. However, if the proximities are considered, product categories 22 and 23 (with slightly smaller complexities) are better connected to other product categories in the value chain. It thus appears to be advisable to target product categories six (basic stainless-steel products) and 40 (metal working moulds and machines) when one is mainly focused on the short-run outcome (maximising complexity) and target product categories 22 (piston engines and automotive related parts) and 23 (laboratory related equipment) when the long-run impact on other product categories is taken into account as well (maximising opportunity gain). This very simple and intuitive example using generic industry data already provides important insights, but still omits many aspects relevant to gaining a nuanced understanding of implications for countries considering following a beneficiation approach to diversification. 
Therefore, we propose a more detailed, country specific IO-PS analysis, which adds another dimension to the above analysis by extending it on three fronts. First of all, the extended framework considers the footprint of the focal country, instead of studying the value chain at a generic worldwide level. Industrial policy at country level needs to take into account which product categories within the country are already performing well - have a large share of their products with an RCA $>1$. The current footprint will determine the difficulty of attaining the remaining products in any given category. For example, acquiring the remainder of the products in categories for which the average $\mathrm{RCA}>1$, may be easier to achieve and therefore unlock other product categories at a lower cost. Second, in order to keep Figure 1 tractable, only the highest proximity values were indicated. One might therefore miss out on selecting product categories that unlock other product categories (within or outside of the focal value chain) through proximities that are not shown in the figure. We use the product space metric of opportunity gain to consider the unlocking of future opportunity throughout the entire product space. Finally, as Figure 1 only considers the proximity of products to other products in the value chain, it ignores the fact that having an RCA in products in other value chains may also reduce the difficulty of attaining products within a product category in the steel value chain due to requiring related capabilities. Thus, we also add the consideration of distance from an entire product space perspective.

Considering the case of steel in South Africa using these three extensions, the beneficiation narrative again seems to be further strengthened when the tier-level case specific metrics are evaluated (Table 1).

It is clear that South Africa is relatively competitive in the first three tiers of the value chain, but not further downstream. ${ }^{6}$ Furthermore, Table 1 indicates the average complexity of, distance to, and opportunity gain of the underlying products within each tier for which South Africa does not yet have an RCA. From the metrics in Table 1, it is clear that the further downstream products have higher distances, but also higher opportunity gains and complexities. Products further downstream can thus be expected to better support economic growth, but it appears to be more difficult to competitively export these products given the current capabilities of South Africa.

Table 1 is where the beneficiation debate generally ends: from the point of view of complexity, it is a good idea to go as far down the value chain as possible but from the point of view of distance, going further down the value chain appears to be difficult. Using the extended country specific metrics, we perform two further analyses. First, we add a more granular analysis to the case study (analysing the product category level); and secondly, we add a dynamic analysis to evaluate the

Table 1. Case specific (South African) metrics aggregated at tier level

\begin{tabular}{|c|c|c|c|c|}
\hline 荠 & 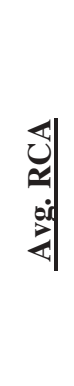 & 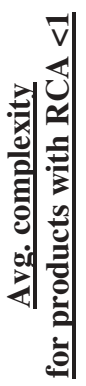 & 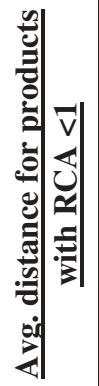 & 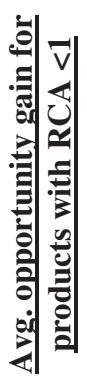 \\
\hline 1 & 5.18 & N/A & N/A & N/A \\
\hline 2 & 6.23 & N/A & N/A & N/A \\
\hline 3 & 4.46 & 0.60 & 0.827 & 0.20 \\
\hline 4 & 0.85 & 0.49 & 0.830 & 0.19 \\
\hline 5 & 0.53 & 0.77 & 0.845 & 0.26 \\
\hline
\end{tabular}


Table 2. Metrics for South Africa at the product category level.

\begin{tabular}{|c|c|c|c|c|c|c|c|c|c|}
\hline $\begin{array}{l}\text { \# } \\
0 \\
0 \\
0 \\
0 \\
0 \\
0 \\
0 \\
0 \\
0 \\
0 \\
0\end{array}$ & 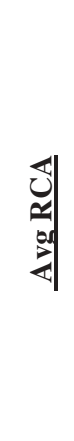 & 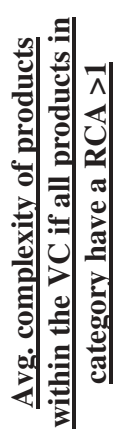 & 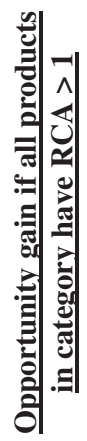 & 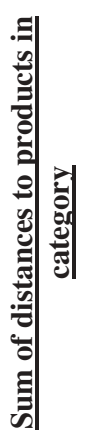 & $\begin{array}{l}\text { \# } \\
0 \\
0 \\
0 \\
0 \\
0 \\
0 \\
0 \\
0 \\
0 \\
0 \\
0 \\
0\end{array}$ & 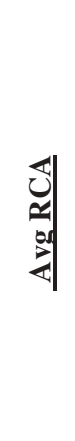 & 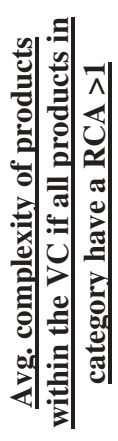 & 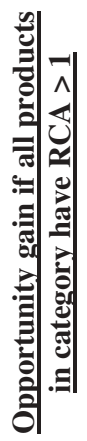 & 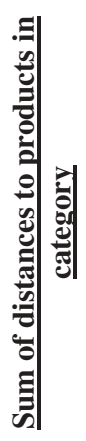 \\
\hline \multicolumn{2}{|c|}{ Baseline } & -0.009 & & & \multicolumn{2}{|c|}{ Baseline } & -0.009 & & \\
\hline \multicolumn{5}{|c|}{ Tier 1} & \multicolumn{5}{|c|}{ Tier 5} \\
\hline 1 & 7.58 & N/A & N/A & N/A & 16 & 0.15 & $0 . \overline{213}$ & 1.67 & 8.62 \\
\hline 2 & 2.79 & N/A & N/A & N/A & 17 & 0.18 & 0.081 & 0.63 & 5.15 \\
\hline \multicolumn{5}{|c|}{ Tier 2} & 18 & 0.24 & -0.025 & 0.24 & 1.66 \\
\hline 3 & 6.23 & N/A & N/A & N/A & 19 & 0.22 & 0.092 & 0.74 & 4.24 \\
\hline \multicolumn{5}{|c|}{ Tier 3} & 20 & 0.22 & 0.116 & 0.92 & 5.87 \\
\hline 4 & 4.46 & 0.034 & 0.32 & 2.48 & 21 & 0.22 & 0.022 & 0.21 & 0.85 \\
\hline \multicolumn{5}{|c|}{ Tier 4} & 22 & 0.59 & 0.177 & 1.20 & 5.05 \\
\hline 5 & 0.80 & 0.003 & 0.65 & 5.68 & 23 & 1.92 & 0.052 & 0.44 & 1.68 \\
\hline 6 & 1.02 & 0.096 & 0.57 & 2.54 & 24 & 0.19 & 0.046 & 0.38 & 1.69 \\
\hline 7 & 0.10 & 0.140 & 1.02 & 4.25 & 25 & 0.49 & 0.027 & 0.29 & 1.67 \\
\hline 8 & 0.35 & 0.040 & 0.54 & 4.14 & 26 & 3.37 & N/A & N/A & N/A \\
\hline 9 & 1.55 & 0.071 & 0.77 & 4.21 & 27 & 1.12 & 0.100 & 0.90 & 5.05 \\
\hline 10 & 0.93 & 0.012 & 0.36 & 1.67 & 28 & 1.78 & -0.099 & 0.50 & 3.96 \\
\hline 11 & 1.01 & -0.023 & 0.02 & 0.80 & 29 & 2.61 & 0.015 & 0.56 & 2.48 \\
\hline 12 & 0.23 & 0.039 & 0.27 & 3.35 & 30 & 0.86 & 0.080 & 0.79 & 4.96 \\
\hline 13 & 0.57 & 0.023 & 0.19 & 1.66 & 31 & 0.50 & 0.050 & 0.73 & 5.95 \\
\hline 14 & 1.05 & -0.028 & 0.10 & 1.60 & 32 & 0.58 & 0.054 & 1.06 & 6.59 \\
\hline \multirow[t]{17}{*}{15} & 0.98 & 0.040 & 0.58 & 7.43 & 33 & 0.40 & 0.059 & 0.48 & 2.51 \\
\hline & & & & & 34 & 0.37 & 0.099 & 0.61 & 3.39 \\
\hline & & & & & 35 & 0.30 & 0.035 & 0.77 & 4.99 \\
\hline & & & & & 36 & 0.12 & 0.022 & 0.44 & 4.27 \\
\hline & & & & & 37 & 0.44 & 0.168 & 1.65 & 8.52 \\
\hline & & & & & 38 & 0.36 & 0.045 & 0.35 & 1.72 \\
\hline & & & & & 39 & 0.55 & 0.125 & 1.12 & 7.50 \\
\hline & & & & & 40 & 0.41 & 0.111 & 0.66 & 2.57 \\
\hline & & & & & 41 & 0.13 & 0.217 & 1.67 & 7.69 \\
\hline & & & & & 42 & 0.39 & 0.099 & 0.85 & 3.38 \\
\hline & & & & & 43 & 0.23 & 0.106 & 0.80 & 3.40 \\
\hline & & & & & 44 & 0.19 & 0.159 & 1.05 & 6.85 \\
\hline & & & & & 45 & 0.29 & 0.106 & 0.92 & 5.93 \\
\hline & & & & & 46 & 0.08 & 0.101 & 0.75 & 6.03 \\
\hline & & & & & 47 & 0.33 & 0.110 & 0.75 & 5.99 \\
\hline & & & & & 48 & 0.16 & 0.187 & 1.26 & 8.52 \\
\hline & & & & & 49 & 0.47 & 0.096 & 0.92 & 7.59 \\
\hline
\end{tabular}


distance, complexity, and opportunity gain trade-offs that countries need to consider when targeting development opportunities under both shorter-term and longer-term strategies.

By simply eye-balling the more granular (static) analysis data (Table 2), we can point out several product categories that would not be primarily targeted if a beneficiation approach were to be taken.

The first column of Table 2 indicates the average RCA for each product category: the higher its value, the more products within that product category already have an RCA $>1$ and/or the higher the RCA of the products for which the $\mathrm{RCA}>1$. The following two columns indicate the average complexity of products in the value chain and total opportunity gain if the product category would be successfully targeted - if the RCA for all products within the product category were rendered higher than 1. Given the fact that the initial value for the average complexity for South Africa is -0.009 , the successful targeting of (almost all $)^{7}$ product groups would increase the average complexity of products within the value chain. Finally, the last column shows the sum of distances to the products in each product category given the current production structure. A higher distance value implies more products and/or more distant products with an $\mathrm{RCA}<1$ within a product category. What can be observed from these metrics is that even though, in general, the distance to products further downstream is higher, the distances to some of the downstream product categories are not. This would suggest that instead of systematically following a beneficiation strategy of first developing the capabilities of competitively producing further upstream products before producing downstream products, South Africa can already target specific downstream activities that should be equally attainable, if not more attainable, and will likely contribute more towards economic development. Thus, the optimal route would imply a sort of 'leap-frogging' when viewed from an input-output perspective.

More in particular, columns 3 and 5 of Table 2 show us that product categories 11 and 21 are easy to obtain ${ }^{8}$ from a distance point of view but targeting them is not strategic from a complexity point of view. Targeting product categories 16, 22, and 41 makes more sense from a complexity point of view but given their higher distances, targeting these product categories would likely require more drastic interventions. When taking a longer-term view, it also becomes important to understand which other product(s) within the product space become unlocked by selecting particular product categories. Column 4 provides a first indication: product categories 16 and 41 , for instance, increase the opportunity gain more than product category 22 .

To further investigate the robustness of these initial findings, we introduce a dynamic analysis to evaluate which of these product categories should be targeted preferably. In the dynamic analysis, we also make a distinction between a shorter-term targeting strategy - focusing on maximising complexity - and a longer term targeting strategy - focusing on maximising opportunity gain. In other words, instead of merely picking the next 'logical' product category suggested by the beneficiation literature based on input-output relations, we allow for the possibility to target that/those product category/-ies in the value chain that maximise either complexity or opportunity gain ${ }^{9}$ given different distance scenarios. In our model, the distance that a country is able to traverse is kept constant under the different strategic regimes. Within this confine, the country seeks to maximise the chosen goal metric by attaining one or more product categories (limited to a maximum of three) ${ }^{10}$ that collectively constitute a cumulative distance that is smaller than or equal to the chosen distance constraint, after controlling for the changes in values after the products in each product category are attained. The results from the simulations are indicated in Table 3 (complexity maximising) and Table 4 (opportunity gain maximising).

In each table, we determine i) the (sequence of) targeted product categories for fixed distance constraints (and the distance use this sequence implies); ii) the resultant average complexity of products within the value chain; and iii) the opportunity gain within the product space. The distance constraints are derived from the frequency distribution of the average distances of products in each of the product categories in the steel value chain to the rest of the product space. It turns out that six of the 49 product categories have an average distance less than 1 (with four having a distance of 0 , as they have no products for which the RCA $<1$ ). The furthest product category has a distance of 8.62. 
Table 3. Model results for complexity maximising case.

\begin{tabular}{|c|c|c|c|c|c|c|}
\hline 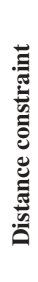 & 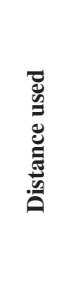 & 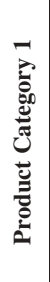 & 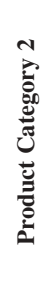 & 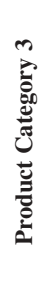 & 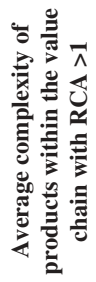 & 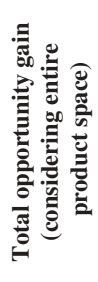 \\
\hline \multicolumn{5}{|c|}{ INITIAL METRICS } & -0.009 & N/A \\
\hline 1 & 0.85 & 21 & 0 & 0 & 0.022 & 0.209 \\
\hline 3 & 2.57 & 40 & 0 & 0 & 0.111 & 0.664 \\
\hline 5 & 4.25 & 23 & 40 & 0 & 0.162 & 1.073 \\
\hline 7 & 6.78 & 6 & 40 & 23 & 0.245 & 1.558 \\
\hline 9 & 8.44 & 40 & 21 & 22 & 0.291 & 1.956 \\
\hline 11 & 10.98 & 22 & 43 & 40 & 0.344 & 2.461 \\
\hline 13 & 11.82 & 7 & 22 & 40 & 0.369 & 2.621 \\
\hline 15 & 14.41 & 7 & 40 & 41 & 0.393 & 2.961 \\
\hline 17 & 16.85 & 7 & 22 & 41 & 0.429 & 3.420 \\
\hline 19 & 18.71 & 16 & 40 & 41 & 0.430 & 3.383 \\
\hline 21 & 20.38 & 7 & 16 & 41 & 0.441 & 3.726 \\
\hline 23 & 21.15 & 22 & 16 & 41 & 0.462 & 3.884 \\
\hline 25 & 21.15 & 22 & 16 & 41 & 0.462 & 3.884 \\
\hline 27 & 21.15 & 22 & 16 & 41 & 0.462 & 3.884 \\
\hline
\end{tabular}

Thus, the maximum distance scenario was set at 27 in order to ensure that any product category combination could be considered for inclusion in the final scenario, given that up to three product categories were considered. By allowing the distance to gradually increase between one and 27 , we are able to study how the optimal combination of products varies depending on the appetite for targeting product categories with higher distances. At the top of each table, we also include the initial metrics so as to compare the scenarios with the initial situation.

Table 3 illustrates the results when product categories are targeted based on their complexities. Clearly, if a larger distance can be traversed, more goods and/or goods of higher complexity will be targeted, therefore increasing the average complexity in the value chain. This clearly also increases the total opportunity gain by unlocking more goods and reducing the average distance to other products. If a more conservative scenario (with a smaller distance) is aimed for, our results suggest targeting (different combinations of) product categories 21 (bearings), 40 (metal working moulds and machines), 23 (laboratory related equipment), and six (basic stainless-steel products). The sum of distances to products within these product categories is relatively low - rendering them reachable at low distances - and they increase the complexity moderately. Under more ambitious scenarios (with greater distance requirements), targeting the more complex product categories seven (basic alloy products) and/or 22 (piston engines and automotive related parts) also become viable. Finally, product categories 16 (textile related machinery) and 41 (machine tools) are only considered under very ambitious scenarios since the sum of the distances to products in these two product categories is very high. As long as the distance constraint is at least 21.15 and a maximum of three product categories can be targeted, the optimal combination is 22, 16, and 41. Increasing the distance threshold further will not alter the optimal combination of these three product categories. Together, they increase the complexity the most. ${ }^{11}$ On a final note, our complexity maximisation never suggests targeting product category 37 (hand tools and related) or 48 (electrical circuit components) while these product categories also have a high complexity. Even though they have high distance requirements, from the static analysis (in Table 2) they seem to unlock other goods in the product space. The obvious question then is whether maximising complexity within the value chain is the optimal 
Table 4. Model results for opportunity gain maximising case.

\begin{tabular}{|c|c|c|c|c|c|c|}
\hline 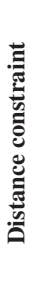 & 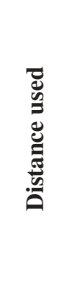 & 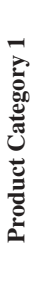 & 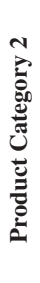 & 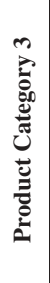 & 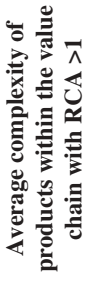 & 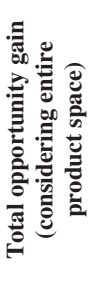 \\
\hline \multicolumn{5}{|c|}{ INITIAL METRICS } & -0.009 & N/A \\
\hline 1 & 0.85 & 21 & 0 & 0 & 0.022 & 0.209 \\
\hline 3 & 2.57 & 40 & 0 & 0 & 0.111 & 0.664 \\
\hline 5 & 4.99 & 10 & 21 & 29 & 0.061 & 1.127 \\
\hline 7 & 6.80 & 40 & 42 & 21 & 0.223 & 1.646 \\
\hline 9 & 8.41 & 40 & 42 & 29 & 0.209 & 2.000 \\
\hline 11 & 10.95 & 22 & 40 & 42 & 0.339 & 2.496 \\
\hline 13 & 12.62 & 7 & 22 & 42 & 0.355 & 2.790 \\
\hline 15 & 14.38 & 7 & 41 & 29 & 0.321 & 3.032 \\
\hline 17 & 16.85 & 7 & 22 & 41 & 0.429 & 3.420 \\
\hline 19 & 18.63 & 41 & 37 & 29 & 0.328 & 3.550 \\
\hline 21 & 20.27 & 7 & 41 & 37 & 0.406 & 3.769 \\
\hline 23 & 21.99 & 22 & 16 & 37 & 0.421 & 3.968 \\
\hline 25 & 24.59 & 16 & 41 & 37 & 0.438 & 4.185 \\
\hline 27 & 24.59 & 16 & 41 & 37 & 0.438 & 4.185 \\
\hline
\end{tabular}

strategy. To consider the impact of rather focusing on the unlocking of other products within the (entire) product space, we move to Table 4 where the opportunity gain is maximised.

Table 4 illustrates the results when product categories are targeted based on their opportunity gain. It is again clear that, generally speaking, if a more ambitious (higher distance) strategy is followed, the product categories with the highest impact on opportunity gain will be targeted. Generally speaking, they will also be the product categories that increase the average complexity in the global value chain and decrease the average distance the most. If a more conservative approach is followed, our results suggest targeting (a combination of) product categories 21 (bearings), 40 (metal working moulds and machines), 10 (basic infrastructure and construction products), 29 (aircraft and related products), and 42 (other tools and manufacturing items). As higher distance strategies are contemplated, targeting product categories seven (basic alloy products), 22 (piston engines and automotive related parts), and/or 41 (machine tools) also becomes attractive. Finally, product categories 16 (textile related machinery) and 37 (hand tools and related) are only interesting candidates under very ambitious distance scenarios since the sum of distances to products in these two product categories are extremely high.

Reassuringly, we find that, generally speaking, maximising complexity and opportunity gain often lead to the same product groups being selected. However, in focusing on the short-term complexity maximisation, we could miss out on targeting product groups that lead to a higher total opportunity gain - product categories 42 (other tools and manufacturing items) and 37 (hand tools and related) are such examples. They not only increase complexity but also unlock possibilities within the whole product space. Targeting such product categories, in other words, facilitates South Africa in the future to disperse its activities more (easily) towards higher complexity goods throughout the product space. Ultimately, we do not identify which product categories South Africa should tackle primarily - this indeed goes beyond the scope of this paper as it depends, amongst other factors, on both the ambitious and the strategic intent of the country (possibly including a variety of the considerations highlighted in the introduction) as well as requires an analysis of the individual factors driving the distance metrics. 
Nonetheless, our IO-PS framework complements the existing value chain-based analyses of beneficiation policy in three ways. Firstly, the IO-PS framework introduces a more detailed and nuanced lens by allowing rapid quantitative analysis at the product category level (and not just the tier level). Thus, it is able to move beyond the high-level narrative emerging at the tier level and uncover the complexities that are apparent at the product category level. Yet, the results are, arguably, more convincing and intuitive than those that have been attained through the application of the PS approach alone. Secondly, the IO-PS framework is able to consider policy strategies within a mineral value chain while efficiently considering the effect of such a strategy on the attainability of products not included in the value chain, but which might require similar capabilities (through the metric of opportunity gain). This thus extends the value chain centricity of the beneficiation literature. Finally, the IO-PS framework brings novel quantitative metrics to the analysis of input-output mappings. These quantitative metrics (distance, opportunity gain, and complexity) provide a rich extension to the collection of tools that already exist to analyse such mappings towards informing policy.

These extensions enable the derivation of a key insight regarding the beneficiation policy debate. Specifically, while tier level metrics seem to support the general beneficiation narrative, the granular (product category) level seems to suggest that a 'leap-frogging' approach is considerably more optimal in terms of return on investment. It thus enables not only a critique on the rationale of following a classical beneficiation policy, but also provides a framework to support improved beneficiation policy decision-making in the future.

\section{Conclusions}

In this paper, we highlighted the multiple factors that need to be considered when setting industrial policy, as well as the lack of appropriate tools to support industrial policy-making. Within this context, we used the capability theory literature (focussing on economic development and the development of strategic export sectors in particular) as a point of departure to contribute towards addressing this need. Specifically, we introduced a novel input-output product space (IO-PS) industrial policy analysis framework that allowed us to gain insights, through a case study, regarding the optimality of implementing beneficiation policy from a capability theory perspective.

The framework consists of utilising the input-output mapping of an industry and identifying product categories. For each of these categories, product space metrics relevant to industrial policy setting are calculated. These metrics include i) distance (providing an indication of the likely difficulty of establishing the competitive production of the relevant products); ii) complexity (indicating the contribution of products to income growth) and; iii) opportunity gain (providing an assessment of the value of the capabilities that will be developed for unlocking future opportunities - both within the focal value chain and the rest of the product space). These metrics are used in a dynamic analysis to identify optimal developmental paths under different distance constraints. We apply this framework to the question of beneficiation through a representative case study of the steel value chain in South Africa. We find that the results broadly support the beneficiation narrative when the unit of analysis is set at the value chain tier level. However, we find that when product categories are considered as the unit of analysis, it seems that a type of 'leap-frogging' approach to industrial policy within mineral value chains is more optimal. We thus developed a framework which enabled a critique on strict interpretations of beneficiation policy and which can be used to guide better industrial policy decision-making.

We see at least three opportunities for further research: firstly, investigating the link between distance and monetary (or other) investment required to attain an RCA $>1$ in the production of a product for which the current $\mathrm{RCA}<1$ (this includes considering the impact of different starting RCA values instead of using - as in this research - binary values); and secondly, refining the conclusions regarding the optimal strategy for development for the case country. In particular, other value chains will also need to be considered regarding their potential to develop high complexity products with high opportunity gain at low distances. Ideally, this will be included in a dynamic analysis which 
considers the opportunities at a product category level in multiple value chains concurrently. Finally, the results from our approach should be complemented with analyses focussing on the other important objectives of industrial policy highlighted in the introduction in order to derive a more holistic view of the merits of targeting industries.

\section{Notes}

1. Including self-discovery externalities, coordination externalities, and missing public inputs.

2. A country's footprint is considered to include those products for which it has an RCA $>1$.

3. The complexities are calculated as the average complexity of all products in the product category (both products with $\mathrm{RCA}<1$ and $\mathrm{RCA}>1$ ).

4. To keep the figure tractable, we only show the 1.3 per cent $(32 / 2352)$ highest proximity linkage values between product categories.

5. For complexity and opportunity gain, higher values are deemed more desirable; for distance, lower values are.

6. South Africa has an RCA in all products within tier 1 and 2 and an RCA for many (not all) products within tier 3.

7. Exceptions are product categories 11 (tanks and related products), 14 (basic aluminium products), 18 (batteries and accumulators), and 28 (ships and related products).

8. 'Obtain' refers to achieving an $\mathrm{RCA}>1$ for all products within the product category.

9. We observe that both concepts generally move in the same direction. Obtaining an RCA in a complex good generally increases the opportunity value as it tends to increase the densities to more complex goods by developing valuable capabilities. In theory, however, it may also decrease the opportunity gain if (i) the extra good itself is extremely complex (thus lowering the average complexity of goods not yet obtained) and/or (ii) the extra good does not contribute significantly to unlocking any other goods (it lowers - or at least does not increase - the average density to high complexity goods not yet obtained).

10. Ideally, no restriction should be placed on the number of product categories included in the analysis and distance should act as the only restriction. However, the number of categories was artificially limited for the practical consideration of computer running time required as it increases exponentially when an additional industry is included. The foresight of three industries was deemed to be sufficient, as various other aspects of the product space may also have changed in the time it takes to acquire three industries, justifying a rerun of the simulation.

11. The selection of these three product categories is a result of a dynamic maximisation process. Looking at Table 3, product category 48 seems to outperform product category 22 when the distance constraint is sufficiently relaxed. However, this is a static result and does not take the dynamics into account - that is the earlier selection of other product categories.

\section{Acknowledgements}

We would like to thank two anonymous referees, the editor, conference participants at ETSG 2017 (Florence) and CGP 2017 (Singapore) as well as seminar participants at KU Leuven and Stellenbosch University for very helpful suggestions to the paper. We also gratefully acknowledge the travel support provided by Stellenbosch University and KU Leuven through the bilateral mobility funding mechanism.

\section{Disclosure statement}

No potential conflict of interest was reported by the authors.

\section{ORCID}

Wouter Bam (D) http://orcid.org/0000-0002-7465-9751

\section{References}

Albeaik, S., Kaltenberg, M., Alsaleh, M., \& Hidalgo, C. A. (2017). Improving the economic complexity index (Arixv Working Paper No. 1707.05826). Cornell University Library. 
Allwood, J. M., Laursen, S. E., Russell, S. N., de Rodríguez, C. M., \& Bocken, N. M. P. (2008). An approach to scenario analysis of the sustainability of an industrial sector applied to clothing and textiles in the UK. Journal of Cleaner Production, 16(12), 1234-1246.

Anejionu, O. C. D., Ahiarammunnah, P.-A. N., \& Nri-Ezedi, C. J. (2015). Hydrocarbon pollution in the Niger Delta: Geographies of impacts and appraisal of lapses in extant legal framework. Resources Policy, 45, 65-77.

Bam, W. (2016). Conceptualising global mineral value chains: A tool for mineral policy design. In Proceedings of the 27th SAIIE Conference (pp. 61-73), Stonehenge in Africa, North West, South Africa.

Bam, W., \& De Bruyne, K. (2017). Location policy and downstream mineral processing: A research agenda. Extractive Industries and Society, 4, 443-447.

Bam, W., \& Schutte, C. S. L. (2017). Proposing a global value chain sustainability analysis framework: Towards the analysis of regional value capture. In SAIIE28 Proceedings, 25th-27th of October 2017 (pp. 477-487). Riverside Sun, Vanderbijlpark, South Africa.

Barnes, J., Kaplinsky, R., \& Morris, M. (2004). Industrial policy in developing economies: Developing dynamic comparative advantage in the south african automobile sector. Competition \& Change, 8, 153-172.

Barrientos, S., \& Smith, S. (2007). Do workers benefit from ethical trade? Assessing codes of labour practice in global production systems. Third World Quaterly, 4, 713-729.

Bocoum-Kaberuka, B. (1999). The significance of mineral processing activities and their potential impact on African economic development. African Development Review, 11, 233-264.

Calderon, A., Harris, J. D., \& Kirsch, P. A. (2016). Health interventions used by major resource companies operating in Colombia. Resources Policy, 27, 187-197.

Chang, H.-J. (1993). The political economy of industrial policy in Korea. Cambridge Journal of Economics, 17, $131-157$.

Chang, H.-J. (2003). Kicking away the ladder: Infant industry promotion in historical perspective. Oxford Development Studies, 31, 21-32.

Cimoli, M., Dosi, D., \& Stiglitz, J. (2009). Industrial policy and development: The political economy of capabilities accumulation. New York, NY: Oxford University Press.

Crowson, P. (2008). Mining unearthed: The definitive book on how economic and political influences shape the global mining industry. London: Aspermont UK.

Cullen, J. M., Allwood, J. M., \& Bambach, M. D. (2012). Mapping the global flow of steel. Environmental Science \& Technology, 46, 13048-13055.

Department: Mineral Resources. (2011). A beneficiation strategy for the minerals industry of South Africa June 2011 (pp. 123). Pretoria: Author.

Department: Trade and Industry. (2017). Industrial policy action plan 2017/18-2019/20 (pp. 1-47). Pretoria: Author.

Du Plessis, J., \& Bam, W. (2018). Comparing the sustainable development potential of industries: A role for sustainability disclosures? Sustainability, 10(878), 1-30.

Felipe, J., Kumar, U., Abdon, A., \& Bacate, M. (2012). Product complexity and economic development. Structural Change and Economic Dynamics, 23, 36-68.

Gereffi, G., Humphrey, J., \& Sturgeon, T. (2005). The governance of global value chains. Review of International Political Economy, 12, 78-104.

Hausmann, R., Klinger, B., \& Lawrence, R. (2008). Examining beneficiation (CID Working Paper No. 162). Harvard University.

Hausmann, R., \& Hidalgo, C. A. (2011). The network structure of economic output. Journal of Economic Growth, 16, $309-342$.

Hausmann, R., Hidalgo, C. A., Bustos, S., Coscia, M., Chung, S., Jimenez, J., .. Yıldirım, M. A. (2011). The atlas of economic complexity: Mapping paths to prosperity (pp. 1-91). Cambridge, MA: MIT Press.

Hausmann, R., \& Klinger, B. (2009). Policies for achieving structural transformation in the Caribbean (IDB Discussion Paper No. 163), Inter-American Development Bank.

Hausmann, R., Klinger, B., \& Lawrence, R. (2008). Examining beneficiation (CID Working Paper No. 162). Harvard University.

Hausmann, R., \& Rodrik, D. (2006). Doomed to choose: Industrial policy as predicament. In Center for International Development Blue Sky Conference Proceedings, Sept. 92006 (pp. 1-64). Harvard University, Cambridge, MA, USA.

Hausmann, R., Rodrik, D., \& Sabel, C. F. (2008). Reconfiguring industrial policy: A framework with an application to South Africa. In 25th Celebration Conference on Entrepreneurship and Innovation - Organizations, Institutions, Systems and Regions Proceedings. (pp. 1-22). Copenhagen, CBS, Denmark.

Henderson, J., Dicken, P., Hess, M., Coe, N., \& Yeung, H. W.-C. (2002). Global production networks and the analysis of economic development. Review of International Political Economy, 9, 436-464.

Hidalgo, C. A., \& Hausmann, R. (2009). The building blocks of economic complexity. Proceedings of the National Academy of Sciences of the United States of America, 106(26), 10570-10575.

Hidalgo, C. A., Klinger, B., Barabasi, A.-L., \& Hausmann, R. (2007). The product space conditions the development ofnations. Science, 317, 482-487.

Hilson, G., \& McQuilken, J. (2014). Four decades of support for artisanal and small-scale mining in sub-Saharan Africa: A critical review. The Extractive Industries and Society, 1, 104-118.

Hirschman, A. O. (1981). Essays in trespassing: economics to politics and beyond. Cambridge, UK: Cambridge University Press. 
Holweg, M., \& Helo, P. (2014). Defining value chain architectures: Linking strategic value creation to operational supply chain design. International Journal of Production Economics, 147, 230-238.

Horner, R. (2017). Beyond facilitator? State roles in global value chains and global production networks. Geography Compass, $11, \mathrm{e} 12284$.

Ivanova, G. (2014). The mining industry in Queensland, Australia: Some regional development issues. Resources Policy, 39, 101-114.

Leontief, W. W. (1936). Quantitative input and output relations in the economic systems of the United States. The Review of Economics and Statistics, 18, 105-125.

Mariani, M. S., Vidmer, A., Medo, M., \& Zhang, Y.-C. (2015). Measuring economic complexity of countries and products: Which metric to use? The European Physical Journal B, 88(293), 1-9.

Morris, M., \& Fessehaie, J. (2014). The industrialisation challenge for Africa: Towards a commodities based industrialisation path. Journal of African Trade, 1, 25-36.

Morris, M., Kaplinsky, R., \& Kaplan, D. (2012). “One thing leads to another"-Commodities, linkages and industrial development. Resources Policy, 37, 408-416.

OEC. (2017). OEC - South Africa. Retrieved October 20, 2017, from http://atlas.media.mit.edu/en/profile/country/zaf/

Peck, F., Connolly, S., Durnin, J., \& Jackson, K. (2013). Prospects for 'place-based' industrial policy in England. Local Economy, 28, 828-841.

Piketty, T., \& Saez, E. (2006). The evolution of top incomes: A historical and international perspective. American Economic Review, 96, 200-205.

Porter, M. (1985). Competitive advantage: Creating and sustaining superior performance. New York: The Free Press.

Pugliese, E., Zaccaria, A., \& Pietronero, L. (2016). On the convergence of the Fitness-Complexity algorithm. European Physical Journal: Special Topics, 225, 1893-1911.

Radetzki, M. (1977). Where should developing countries' minerals be processed? The country view versus the multinational company view. World Development, 5, 325-334.

Ramirez, P., \& Rainbird, H. (2010). Making the connections: Bringing skill formation into global value chain analysis. Work, Employment \& Society, 24, 699-710.

Reinhardt, N. (2000). Back to basics in Malaysia and Thailand: The role of resource-based exports in their export-led growth. World Development, 28, 57-77.

Rolfe, J. (2013). Predicting the economic and demographic impacts of long distance commuting in the resources sector: A surat basin case study. Resources Policy, 38, 723-732.

Rudberg, M., \& Olhager, J. (2003). Manufacturing networks and supply chains: An operations strategy perspective. Omega, $31,29-39$.

Seuring, S. (2013). A review of modeling approaches for sustainable supply chain management. Decision Support Systems, 54, 1513-1520.

Spring, M., Hughes, A., Mason, K., \& McCaffrey, P. (2017). Creating the competitive edge: A new relationship between operations management and industrial policy. Journal of Operations Management, 49-51, 6-19.

United Nations. (1984). Mineral processing in developing countries: A discussion of economic, technical and structural factors. London: Graham \& Trotman Ltd. 